\title{
TEOLOGÍA POLÍTICA, ANGELOLOGÍA Y ANTROPOMORFISMO: EL PROBLEMA DE LA SECULARIZACIÓN EN EL JUDAÍSMO
}

\author{
Emmanuel Taub1
}

Conicet

Recibido: 29.04.2019 - Aceptado: 29.10.2019

\begin{abstract}
RESUMEN
Entendiendo la teología política como aquellos actos y conceptos políticos en los que subyace un resto que los sobrepasa y que los vincula con una dimensión que reside más allá de lo humano, el objetivo de este artículo es analizar los avatares de este concepto desde la matriz de la tradición judía. Es por ello que se intentará realizar un corrimiento y una relectura de los debates modernos de la teología política cristiana y la secularización desde el judaísmo. Adentrándonos también por los caminos de la mística judía, nuestro objetivo es comprender de qué manera se produce un fenómeno inverso al de la así llamada secularización, por el cual los conceptos políticos se mueven a la esfera de lo divino y no al inverso. Para conseguir demostrar esta idea, se retomarán las concepciones angelológicas del judaísmo así como, principalmente, la idea antropomórfica de la cábala, buscando construir otra forma de leer nuestra realidad política, entendiéndola como aquello que constituye un "pálido reflejo", o una "huella residual", de las formas políticas divinas en este mundo.
\end{abstract}

Palabras clave: Antropomorfismo; Angelología; Judaísmo; Teología política; Judaísmo.

\begin{abstract}
This paper seeks to understand, from the point of view of Jewish Political Theology, those acts and political concepts that exceed and cannot by explained by human reason and that, at the same time, are related to a dimension beyond the human. Thus, the main objective of this article is to analyze the concept of Political Theology from the perspective of the Jewish tradition. We will start our research by introducing the modern Christian Political Theology debate, in particular its concept of secularization, and we are going to address such debate from the perspective of Judaism. Drawing on important concepts from Jewish Mysticism, our objective is also to understand how in Judaism secularization occurs like an inverse phenomenon. In order to think about this idea, we will analyze the angelological conceptions of Judaism, in particular the anthropomorphic idea in Kabbalah, in order to present and build upon an alternative way of reading our political reality: understanding reality as that which constitutes a "pallid reflection", or a "residual trace", of divine policies in this world.
\end{abstract}

Keywords: Anhtropomorphism; Angelology; Political Theology; Judaism.

\footnotetext{
${ }^{1}$ emmanueltaub@gmail.com
} 
"Como no hay teología sin implicaciones políticas, tampoco hay teoría política sin presupuestos teológicos”

Jacob Taubes $(2007,266)$.

I.

En su Primera Epístola a los Corintios, Pablo de Tarso dice:

“Así, mientras los judíos piden milagros ${ }^{2}$ y los griegos buscan sabiduría, nosotros predicamos a un Cristo crucificado: escándalo para los judíos, locura para los gentiles; mas para los llamados, lo mismo judíos que griegos, un Cristo, fuerza de Dios y sabiduría de Dios. Porque la locura divina es más sabia que los hombres, y la debilidad divina, más fuerte que los hombres" (I Cor. 1: 22-25).

Son estas las palabras con las que Pablo marca el rumbo dialéctico de la historia universal: los judíos buscan observar los signos de Dios en el mundo, los milagros, mientras que los griegos, antitéticamente, persiguen la sabiduría; y en esta relación dialéctica la síntesis es para los "llamados", aquellos que predican sobre el Mesías crucificado. Al mismo tiempo, con este gesto, Pablo nos introduce en lo incognoscible, en la posibilidad de pensar la locura y la debilidad divina: locura que es más sabia que los hombres y debilidad que es más fuerte aún que ellos, porque los misterios de los atributos divinos, parece decirnos, están más allá de las capacidades de comprensión del ser humano.

Siguiendo por el camino aquí inaugurado por el apóstol, debemos comenzar nuestra reflexión preguntándonos qué es un milagro, elemento identificado con la búsqueda o los pedidos del pueblo judío. Un milagro comúnmente es entendido como la intervención divina en el mundo, con o sin intermediarios, o sea, directamente ejecutada por Dios o realizada a través de sus mediadores, ya sean estos partes del reino celestial o del mundo terrenal. ${ }^{3}$ El milagro es un hecho en la naturaleza que lo corre de lo ordinario y del ciclo natural de las cosas: algo

\footnotetext{
nos".

${ }^{2}$ Dependiendo de la traducción, también la palabra "milagros" puede aparecer como "sig-

${ }^{3}$ Para una defenición del milagro en el judaísmo véase: Kohler 1906, 606-607; Maimónides 2005, 435-438; Baron 1968a, 22-30.
} 
fuera de lo "normal", algo in-explicable. Esto, justamente, pareciera haber entendido Carl Schmitt cuando, en el capítulo tercero de su Teología política escribe que: "El estado de excepción tiene para la jurisprudencia análoga significación que el milagro en la teología" (Schmitt 2009, 37). ¿Qué nos quiere decir Schmitt con este dictamen tan conocido y trabajado?

Partiendo de la concepción del milagro como intervención divina en el mundo de los hombres, en primer lugar, podemos comprender que las palabras del jurista alemán introducen el poder legislativo divino dentro de un aparato legal, ya sea como parte de la ciencia del derecho o como parte del conjunto de sentencias y fallos dictados por tribunales o autoridades gubernamentales, o sea, como parte de la arquelogía del derecho. Los milagros son actos que transforman el transcurso "normal" de las cosas para volverlas algo extra-ordinario, de la misma manera que el "estado de excepción" constituye un hiato en la ley determinado por el poder soberano, que transforma "lo normal" en extra-ordinario y excepcional. $^{4}$

Por otro lado, en segundo lugar, Schmitt ubica a todo aquel, ya sea persona u órgano gubernamental, que puede declarar el estado de excepción dentro de la órbita de la teología, ya que -según su propia concepción de la teología políticaexiste una transferencia o corrimiento de los conceptos teológicos a través de un proceso de secularización hacia los conceptos de la teoría del Estado (Schmitt 2009, 37). Observamos, así, que el estado de excepción como concepto político se constituye en el ámbito de los conceptos del Estado pero como un corrimiento del sentido del milagro desde el ámbito teológico.

Podemos hacernos entonces la siguiente pregunta: ¿Este corrimiento no arrastra o conserva consigo también una huella teológica imborrable que constituye, en definitiva, el nomos oculto de su poder constitutivo y de su fuerza legítima?

Antes de responderla, regresemos a la definición de Schmitt sobre la teología política, a su famosa y repetida sentencia de que "todos los conceptos centrales de la moderna teoría del Estado son conceptos teológicos secularizados"5 (Schmitt 2009, 37). Podemos observar, en principio, que la secularización es este corrimiento de los conceptos que se da, ante todo, como un acto lingüístico por

${ }^{4}$ Para una historia de la figura del "estado de excepción” tan caro a nuestro tiempo así como también de su problematización, véase: Agamben 2004; Schiavone 2012; Ludueña Romandini 2010; Galli 2011.

${ }^{5}$ Como bien explica Carlo Galli, el término "teología política" no fue inventado por Schmitt sino que, en el siglo XX, es quien "lo reinventa" y lo reintroduce en los debates sobre Teoría Política, Filosofía y Derecho: "se le debe a él el primer impulso de la larga circulación del término que se desarrolló en un sentido fuertemente crítico con respecto a su primer responsable" (Galli 2011, 61). Sobre el problema moderno de la teología política desde diferentes perspectivas, además del trabajo de Erik Peterson que veremos con atención más adelante, véase: Taubes 2007; Marramao 1998; Metz 2002. 
el cual se traslada o re-significa un concepto que pertenecía al ámbito de la teología hacia el ámbito de la teoría del Estado, o sea, hacia el ámbito de la política (comprendiendo también al Estado como el actor principal de la política moderna). Sin embargo, este corrimiento o resignificación no lleva consigo naturalmente un vaciamiento o desaparición del sustrato teológico o divino que reside dentro del concepto resignificado por el solo hecho de pensarlo ahora en el ámbito político. Más aún, con sólo pensar en el origen conceptual y lingüístico de los conceptos políticos a través de la historia universal que llega a nuestro mundo moderno desde la Antigüedad del Imperio Romano y su articulación con el Cristianismo, se hace imposible pensar en la desaparición del sustrato teológico de los conceptos políticos de forma absoluta y determinante. Por lo que nos gustaría sugerir que las huellas teológicas continúan presentes allí, moldeando desde las oscuridades de los caminos transitados y olvidados por el bosque de la historia, los conceptos políticos "supuestamente" secularizados. Con esto, lo que intentamos señalar es que el problema moderno de los conceptos de la teoría del Estado, y con ello de la política, ha abandonado la importancia de la convivencia de lo teológico y lo político al imaginar y construir la institucionalidad estatal y gubernamental desde la base de la razón humana, operativa como libre de elementos incognoscibles e inexplicables, cuando justamente el malestar que producen (así como el secreto de su legitimidad) al pensamiento racional moderno se debe a que nunca han perdido vinculación con la dimensión de lo divino o de lo teológico. $^{6}$

En la presencia como concepto vacío, el concepto sigue existiendo y regulando el significado que se le ha intentado dar. De esta manera, podemos comprender que cuando Nietszche escribió en palabras de "El loco" que "Dios ha muerto" (Nietszche 2009), o cuando Gershom Scholem explica, reflexionando sobre el nacimiento de la mística judía, que la voz de Dios ya no puede oirse (Scholem 2000) esto no determina para la tradición judía la desaparición de Dios, sino tan sólo su ocultamiento, su contracción o corrimiento para la existencia y la creación del ser humano y del mundo, así como también para la existencia de la Ley revelada. Más aún, si leemos con atención este "supuesto" corrimiento desde el pensamiento de, por ejemplo, el gran pensador judeo-alemán Franz Rosenzweig expuesto en su gran obra La estrella de la redención, en realidad estamos observando de qué manera Dios, que pertenece a una dimensión identificada como "antemundo", se "revela" al Hombre a través de la Ley y "crea" a través de la narración el Mundo, pero nunca coincidiendo en la misma dimensión con lo creado o revelado (Rosenzweig 2006). Para la tradición judía, ya el mismo texto bíblico establece uno de los misterios más importantes de la relación entre

${ }^{6}$ Desde esta perspectiva habría que releer con nuevos ojos los trabajos de Max Weber sobre el Capitalismo, así como también resaltar la importancia del fragmento incompleto de Walter Benjamin El capitalismo como religión. 
Dios y el hombre: que el ser humano no puede ver a Dios y seguir viviendo. Así dice el libro del Éxodo:

"Le dijo Moisés [a Dios]: Muéstrame Tu gloria. Él le respondió: Yo haré pasar toda Mi bondad ante ti, y revelaré el Nombre del Señor en tu presencia. Cuando quiera congraciarme, Me congraciaré; y cuando quiera compadecerme, Me compadeceré. Y agregó: Tú no podrás ver Mi rostro, pues ningún ser humano puede ver Mi rostro y seguir viviendo. Dijo entonces el Señor: Mira, tengo un lugar especial (para ti) -párate sobre la roca y cuando pase Mi Gloria Yo te ubicaré en una grieta y cuando pase Mi Gloria, Yo te ubicaré en una grieta de la roca y te protegeré con Mi mano hasta que Yo haya pasado. Después quitaré Mi mano para que Me veas por atrás [y verás mis espaldas], pero Mi rostro no se puede ver" (Éxodo 33:1-23).

Digamos entonces: Dios no ha muerto sino que ya no significa, ya no se lo puede identificar como la unión entre concepto y sentido, sino que se ha separado la vasija de su contenido. La cuestión que debemos comprender entonces no es de qué forma lo divino y lo humano han dejado de estar "juntos", si es que alguna vez lo estuvieron, sino que para la tradición judía en realidad han sido mediados por lo otro. Es esto parte constitutiva del pensamiento judío: la relación entre la divinidad y el hombre es una relación de imposibilidad de con-vivencia en un mismo espacio o dimensión. Esto se puede observar desde la tradición exegética, rabínica y filosófica del texto bíblico, así como también desde la propia tradición mística y esotérica judía que, desde finales del siglo XII y principio del siglo XIII con el surgimiento de la Cábala, ha caracterizado el mundo de lo divino a través de las 10 emanaciones de Dios o "mundo de las sefiot" dejando un lugar reservado a lo incognoscible desde donde estas emanaciones surgen, lo que han llamado Ein Sof o "sin final".

Trasladando estos elementos y esta forma de comprender la relación entre lo divino y lo mundano al mundo de las ideas, de los conceptos y de las formas linguíísticas, podríamos sugerir que el corrimiento desde la teología a los conceptos centrales de la teoría del Estado -y de la política- como lo presentara Schmitt, no hace más que confirmar esa dimensión primordial de lo divino y lo mundano, y con ello también nos invita a la interpretación desde la teología política judía de indagar sobre la existencia de las mediaciones entre ambas dimensiones como

${ }^{7}$ Como bien explica Scholem, tomando para ello el punto más elevado de la cábala judía expuesto en el Zóhar, allí se distinguen claramente dos mundos que representan a Dios: "En primer lugar, un mundo primario, que es el más profundamente oculto de todos, imperceptible e inintelegible para todos salvo para Dios: es el mundo del Ein-sof. En segundo lugar, otro mundo, ligado al primero, que posibilita el conocimiento de Dios y del cual la Biblia dice: 'Abre las puertas para que yo pueda entrar'. Es el mundo de los atributos. [...] Según los cabalistas, hay diez atributos fundamentales de Dios, que constituyen, al mismo tiempo, diez estados por los cuales va y viene la vida divina" (Scholem 2000, 230), estos atributos se llaman "sefirot". 
la posibilidad misma de la existencia de un arte de lo político. En cuanto a las mediaciones, ellas pueden ser desde la figura del Mesías o de los ángeles y la burocracia angelológica, así como las revelaciones proféticas a través de los sueños o el lugar del Libro revelado, la Torá o Pentateuco.

\section{II.}

Conocida es la disputa en torno a la teología política que llevaron adelante durante parte del siglo XX Carl Schmitt y Erik Peterson, especialmente sobre la imposibilidad de una teología política cristiana según este último y la respuesta posterior de Schmitt. ${ }^{8}$ Luego de su disputa, todo el camino que desde finales de la Segunda Guerra Mundial a nuestros días han recorrido los trabajos de Johann Baptist Metz, Giacomo Marramao, Giorgio Agamben y Fabián Ludueña Romandini entre otros, marcan la importancia del problema teológico-político en la Filosofía Política actual. De entre todos ellos, el que a nuestro entender representa hoy una de las miradas más interesantes sobre la teología política y el debate de la secularización dentro del mundo judío es el trabajo realizado por el egiptólogo Jan Assmann. En particular su libro Poder y salvación constituye una lectura estructurada, revisada y reescrita de su mirada sobre lo que llama la teología política, o sea, "las cambiantes relaciones entre comunidad política y ordenamiento religioso o, dicho más breve, entre poder y salvación" (Assmann 2015, 11-12) en el Antiguo Egipto e Israel. Esta relación gira en torno a dos preocupaciones: las implicaciones teológicas de lo político y, por otro lado, las implicaciones políticas de lo teológico (Assmann 2015, 12). Assmann propone para sus indagaciones dar vuelta la frase de Schmitt diciendo que "todos los precisos conceptos -o quizás prefiramos decir, más modestamente: algunos conceptos centrales- de la teología son conceptos políticos teologizados" (Assmann 2015, 29) y así puede caracterizar de modo inverso también al proceso de secularización como un proceso de "teologización" en el cual los conceptos políticos se teologizan hasta llegar a

${ }^{8}$ Erik Peterson enfrenta los postulados de su amigo Schmitt intentando negar la tesis del jurista alemán sobre la posibilidad de una teología política. Esta respuesta es desarrollada en su texto El monoteísmo como problema político de 1935, en donde analiza, para demostrar su tesis sobre la imposibilidad de pensar una teología política desde el cristianismo, que el monoteísmo como problema político surgió de la "elaboración helenista de la fe judía" a través del concepto de "monarquía divina" (Peterson 1999, 94). Idea teológico-política que la Iglesia asume de manera propagandística al expandirse a través del Imperio romano pero que luego colisiona, ella, con una concepción pagana de teología política. Según Peterson, "los cristianos, para poderse oponer a esa teología pagana cortada a la medida del imperio romano, respondieron que los dioses nacionales no pueden gobernar porque el imperio romano significa la liquidación del pluralismo nacional" (Peterson 1999, 94-95). Por ello, luego, la Pax Augusta se explicó como cumplimiento de las profecías escatológicas del Antiguo Testamento. Sin embargo, la doctrina de la monarquía divina, continúa Peterson, tropieza con el dogma trinitario y la interpretación de la Pax Augusta con la escatología cristiana, y "así no sólo se acabó teológicamente con el monoteísmo como problema político y se liberó a la fe cristiana del encadenamiento al imperio romano, sino que se llevó a cabo la ruptura radical con una 'teología política"” (Perterson 1999, 95). La respuesta de Schmitt a este texto se produjo 34 años después, en su escrito Teología política II. 
afirmar, no sin polémica, que en el ejemplo del mundo egipcio antiguo así como en el de Israel, "la religión nace del espíritu de lo político" (Assmann 2015, 29).

En sus reflexiones sobre la teología política judía, Assmann se centra en la figura de Moisés, y desde ella explica que, fuera de la discusión historiográfica sobre su figura, hay que preguntarse sobre él como una "figura del recuerdo" para ocuparse así de su papel en la formación del pueblo de Israel y de una teología política (Assmann 2012, 99; Assmann 2015, 283-321). Siguiendo con este argumento, Assmann escribe que Moisés es un teólogo político que busca "trasladar a la política una nueva teología mediante la legislación y la fundación de una nación" y para ello busca "legitimar teológicamente un orden político" (Assmann 2012, 114). Es desde este punto en el que el elemento de la prohibición de las imágenes de Dios se transforma en uno de los ordenamientos fundacionales de la Ley judía, pensando así en una teología política iconoclasta, en la que es posible construir una teología política en donde, según el egiptólogo, "el poder, el gobierno, el orden y la justicia provienen de Dios" (Assmann 2012, 117) y en donde Él, Dios, ejerce directamente el poder al promulgar las leyes e impartir justicia. Es por ello que para Assmann el monoteísmo bíblico debe ser leído como un "movimiento esencialmente político" (Assmann 2015, 283) que va aparejado a la figura de Moisés, y por ello llegará a decir que "en el mundo conceptual del siglo XVIII, la teología política de Moisés es una teología pública y constitutiva de lo público. Las leyes mosaicas establecen [...] una existencia política en un ámbito de responsabilidad pública" (Assmann 2015, 284).

Ahora bien, para Assmann, lo público se diferencia del misterio y de lo oculto, pero no de lo privado, y es el carácter de lo público lo que caracteriza lo político y lo deja al descubierto. Sin embrago, creemos que aquí radica nuestra mayor diferencia con los planteos del egiptólogo, ya que no es posible pensar en la figura de Moisés como fundamento de lo político desde la teología sin ver que ello contiene un movimiento en el que se constituye, desde la tradición judía, una teología política quitando el componente divino del mundo directamente: el surgimiento del relato divino sobre la creación del mundo re-significa la historia a través de una narrativa que no viene a suplantar la historia sino a divinizarla, esto quiere decir, a volver al hombre responsable sobre ella como presupuesto de la revelación divina. Y, por otro lado, esto conforma una teología política y no una política teológica, como finalmente pareciera suponer la investigación de Assmann, porque lo esotérico -lo oculto- también determina para el judaísmo los arcanos de la política. Al mismo tiempo, al centrar su análisis solamente en la figura de Moisés, Assmann deja de lado las diferentes mediaciones que son las formas fundamentales con las que el mundo divino incide activamente, como veremos, en el mundo terrenal. 
III.

Dicho todo esto, entendemos la teología política desde la tradición judía como aquellos actos y conceptos políticos en los que subyace un resto que lo sobrepasa y lo vincula con una esfera que se relaciona con una dimensión que reside más allá de lo humano: con lo divino y con las formas de la divinidad. En ese sentido, es posible pensar en una teología política judía por fuera del desarrollo histórico de la secularización de los conceptos de la teología cristiana. En primer lugar, porque con el advenimiento del cristianismo, y su articulación con el Imperio Romano, el tiempo histórico queda determinado por el tiempo mesiánico cristiano, mientras que el pueblo judío se ubica al costado de la historia, negando repetidamente durante toda su historia, incluso hasta nuestros días, el advenimiento de un Mesías verdadero que traiga consigo el inicio del final de los tiempos (o del tiempo mesiánico). Es por ello que, podríamos sugerir, la historia judía es la historia de la negación del Mesías. Y, en segundo lugar, porque consideramos que es posible desde esta visión marginal enriquecer al debate y la reflexión sobre una teología política de los conceptos políticos. La teología política judía encuentra en el mesianismo el dispositivo que articula lo político y lo ético, lo nacional y lo universal, instalándose entre estas dimensiones (Taub 2013). Pero sin embargo, el ideal mesiánico no es la única mediación que se ubica entre las dimensiones espaciales que hacen al cielo y a la tierra. Es necesario incluir también las figuras angelológicas como parte de la problematización de una teología política judía (Taub 2018).

En este sentido, y complementando nuestros anteriores trabajos, debemos decir que, primero, la teología política en el judaísmo muestra una relación activa entre lo divino y lo mundano, y que nunca ha dejado de existir; segundo, sólo podrá haber teología política judía mientras existan mediadores que conecten activamente -ya sea como esperanza en un tiempo porvenir mesiánico o en la administración angelológica del universo- lo divino y lo mundano; y tercero, que la función mediadora de las dos figuras señaladas, el Mesías por un lado y los ángeles por el otro, introduce una nueva caracterización en donde el primer modelo de teología política judía queda determinado desde lo terrenal hacia lo celestial (o desde lo mundano hacia lo divino) ya que está construido sobre la imagen de un Mesías persona que siempre está llegando (la potencial de la esperanza mesiánica) y que desde la tierra (y la historia) conecta lo que podríamos caracterizar como el abajo con el arriba. Mientras que, por otro lado, el segundo modelo de teología política judía está representado por la mediación de las figuras angelicales quienes activamente vinculan el arriba con el abajo. El primer caso se corresponde entonces a un modelo que gira en torno a una figura que representa el poder mediador y transformador de manera personal, y contiene todas aquellas políticas teológicas que se levantan frente a la figura de líder carismático, pero 
también peligrosamente totalitario, mientras que las segundas quedan representadas en un modelo angelológico-burocrático que se basa en la administración jerárquica. ${ }^{9}$

Podríamos decir que tanto la figura del Mesías como la burocracia angelológica son mediaciones que unen las dimensiones de lo divino con las de lo mundano, dando origen a la teología política judía en donde lo teológico y lo político constituyen parte del mismo entramado. Y desde éste, se materializan tanto las instituciones políticas como las conceptualizaciones lingüísticas en donde las huellas de lo divino siguen conservando su función legitimadora.

IV.

El rasgo particular de lo que simboliza pensar la teología política y los procesos de secularización desde el judaísmo es la concepción de que en realidad estamos trabajando sobre la relación activa entre la dimensión divina y la mundana, y que por ello es el papel de los mediadores, o puentes, el fundamento de uno de los más grandes misterios y problemas para la propia tradición, así como para sus relecturas. Cuando nos referimos a ello como un problema, estamos pensando en los esfuerzos históricos por parte del rabinismo, por un lado, y de la filosofía racional judía -con la figura de Maimónides como su mayor representante- hasta de la Haskalá (o Iluminismo judío) entrado el siglo XX por otro lado, por neutralizar o solapar el papel fundamental que en la administración del mundo y del universo tienen las figuras del Mesías como la de los ángeles. ${ }^{10}$

Debemos decir, entonces, que uno de los ejemplos más radicales de esta postura "contra-secularizante", o "teologizante", en la tradición judía es el ejemplo de la angelología. Dentro del amplio corpus angelológico del judaísmo ${ }^{11}$, hemos decidido presentar aquí ejemplarmente un pasaje lo suficientemente ilustrativo que nos permita visualizar la injerencia de los ángeles en el mundo y en la política de los hombres, y que además se encuentre por fuera de las variadas apariciones que son fácilmente rastreables dentro del texto bíblico. Hacemos referencia al famoso herem $^{12}$, o edicto de excomunión, contra Baruch de Spinoza del 27 de julio de 1656. Repasemos una de las partes fundamentales de su estructura:

\footnotetext{
${ }^{9}$ Queda así planteado el camino a seguir en nuestras futuras investigaciones: ¿Cuál es la relación entre ambas mediaciones y qué presupuestos trae aparejados la vinculación Mesías-ángeles para la teología política?

${ }^{10}$ Para ampliar el análisis sobre las transformaciones del rabinismo vinculadas a los temas planteados, véase: Cohen 1965; Baron 1968b. Para analizar los cambios generados por la figura de Maimónides, véase: Guerrero 2004; Kraemer 2010; Bensussan 2014. Finalmente, sobre la Haskalá o Iluminismo judío, véase: Baron 1965; Brenner 2012.

${ }^{11}$ Véase especialmente: Agamben y Coccia 2009; Taub 2018.

12 Para ampliar el estudio sobre el uso teológico-político del herem, véase: Taub 2016.
} 
"Por la decisión de los ángeles, y el juicio de los santos, excomulgamos, expulsamos, execramos y maldecimos a Baruch de Spinoza, con la aprobación del Santo Dios y de toda esta Santa comunidad, ante los Santos Libros de la Ley con sus 613 preceptos, con la excomunión con que Josué excomulgó a Jericó, con la maldición con que Eliseo maldijo a sus hijos y con todas las execraciones escritas en la Ley. Maldito sea de día y maldito sea de noche; maldito sea cuando se acuesta y maldito sea cuando se levanta; maldito sea cuando sale y maldito sea cuando regresa. Que el Señor no lo perdone jamás. Que la cólera y el enojo del Señor se desaten contra este hombre y arrojen sobre él todas las maldiciones escritas en el Libro de la Ley. El Señor borrará su nombre bajo los cielos y lo expulsará de todas las tribus de Israel abandonándolo al Maligno con todas las maldiciones del cielo escritas en el Libro de la Ley. Pero vosotros, que sois fieles al Señor vuestro Dios, vivid en paz" (Dominguez 1995, 186-187).

En este pequeño y contundente texto, quedan bien expresados los diferentes elementos que hacen a la presencia de lo sagrado y, en especial, de los ángeles mediadores en la administración del gobierno celestial como también en el reino terrenal. Y, además, muestra de qué manera el herem bíblico pasa de ser un dispositivo jurídico de apropiación y consagración de un espacio del mundo por mandato de Dios en el texto bíblico a un instituto jurídico intracomunitario en donde lo divino y lo mundano quedan sellados definitivamente en su uso terrenal: en el castigo de la excomunión.

Podemos observar que su valor de verdad está dado, en primer lugar, por su vinculación directa con la soberanía divina: la expulsión está decidida en consenso entre el rabino, la comunidad y los ángeles, que son quienes realmente deciden la excomunión de Spinoza. Este elemento es sumamente relevante porque visibiliza dos cuestiones de gran importancia: primero, que el herem como instituto jurídico intracomunitario materializa y legitima el vínculo entre lo divino y lo mundano de la misma manera que lo tenía en su origen bíblico, como un mandato divino directo hacia el pueblo de Israel (Taub 2016); y, segundo, se observa la manera en la que los ángeles se convierten en los veedores de la decisión consagrada a través del herem, o sea, del castigo, que de esta manera se encuentra legitimado y sustentado por Dios, por las Escrituras y por los 613 preceptos. Como lo muestra el herem contra Spinoza, se vuelve imprescindible la función gubernamental de los ángeles para mantener y administrar el orden terrenal adherido al orden divino, ahora a través de la decisión de los castigos, tanto en la tierra como en los cielos. 
El propio Maimónides, en su batalla contra la mística judía de su tiempo, ${ }^{13}$ escribe en su Guía de perplejos que "nunca encontrarás realice Dios ( ¡ensalzado sea!) acto alguno sino por ministerio de un ángel" (Maimónides 2005, 254). Sin embargo, detrás de las palabras del gran rabino y filósofo existe oculto un objetivo teológico-político: la búsqueda de racionalización de las funciones gubernamentales de los ángeles dentro de la tradición judía. Es esta necesidad de Maimónides por racionalizar el problema angelológico, primero como el correlato aristotélico de las inteligencias separadas que mueven las esferas celestiales y al Intelecto agente (Maimónides 1991, 7; Maimónides 2005, 250-251) y, segundo, describiéndolos como mensajeros ejecutantes de las órdenes divinas pero bajo la imposibilidad y prohibición de ser adorados, idolatrados o comparados con la divinidad (Maimónides 2005, 253), que terminará constituyendo el futuro solapamiento y aniquilación de la angelología judía por parte del rabinismo como respuesta a los peligros que conllevan las figuras de estos supuestos "hijos de Dios" e intermediarios entre el poder divino y el mundo de los hombres. Peligros que podrían llevar a quebrantar o transgredir la idea del Dios Único monoteísta como pilar fundacional de la tradición judía, habilitando así, por un lado, la posibilidad de co-existencia dentro de la soberanía divina de diferentes poderes decisores y administrativos y, por otro, la idea de que el poder soberano divino no se halla concentrado en la unicidad (y totalidad) de Dios sino en una burocracia angelológica que mantiene vivo el funcionamiento del universo. ${ }^{14}$ Además, y no menos importante, el problema de la filiación de los ángeles y su rol dentro de la economía divina también, para la visión rabínica, podría permitir una lectura extensiva como las interpretaciones cristianas que unen la idea del "hijo del Dios" con la Jesús-Mesías.

Quitándonos desde aquí las ataduras de estas lecturas conservadoras, nos gustaría señalar la importancia de la figura de los ángeles para la tradición teológico-política judía. Volviendo con ojos libres de temor y temblor al texto bíblico encontramos que los ángeles no sólo aparecen a lo largo y ancho del cánon de los textos canónicos judíos sino que allí es posible observar de qué manera cumplen diferentes funciones que van desde la transmisión y enseñanza de diferentes oficios y secretos divinos a los hombres, como de la comunicación de las decisiones de Dios en cuanto transmisores y ordenadores entre el reino de los cielos y el reino de la tierra o, por último, también como guías del pueblo de Israel por los caminos del desierto y de la historia. ${ }^{15}$

Existe una convivencia activa entre el mundo celestial y el mundo terrenal a través de la función burocrático-administrativa de los ángeles. Es así que se

\footnotetext{
${ }^{13}$ Para un desarrollo de esta problemática histórica véase: Laenen 2006; Idel 2005.

${ }^{14}$ Sobre esta problemática particular, además de remitir a nuestros trabajos ya citados, recomendamos especialmente: Barker 1992; Segal 2012.

${ }^{15}$ Sólo se necesita abrir el Pentateuco (Torá) para encontrar cientos de ejemplos sobre la relación de los ángeles junto al pueblo de Israel.
} 
conforma una relación socio-angelológica entre los ángeles y los hombres que se reparten las funciones en la administración de la comunidad y el mundo, como también en la vida política de los pueblos. Observamos de esta forma que la aparición de los ángeles en el herem contra Spinoza cuando éste dice "Por la decisión de los ángeles, y el juicio de los santos" no es un mero recurso estilístico o decorativo, sino que en realidad está develando el funcionamiento del verdadero dispositivo soberano divino y dejando al descubierto el nomos oculto de la relación política y social entre el mundo divino y el mundano así como el fundamento de la legitimidad de sus instituciones. Consecuencia ésta de la comunión entre los seres celestiales y los seres terrenales que se hallan asociados en la administración, el culto y las batallas, y que nos enseña que el poder soberano, realmente, no es el que decide sobre el estado de excepción como dijera Carl Schmitt, sino el que liga lo divino y lo mundano.

\section{V.}

Acomodados ya por este camino sinuoso, quiséramos dejar aquí planteados los rastros de una investigación en curso que retoma el problema de los antropomorfismos en el judaísmo desde la perspectiva de la cábala judía como otra forma de comprender nuestra realidad, el sentido de la realidad, así como también la teología política judía y la figura de los ángeles. El problema de los antropomorfismos es el problema de las cualidades de Dios en donde éste, en la Biblia, es descrito de forma humana. El objetivo es observar y pensar desde allí de qué manera estas las figuras teológico-políticas son, desde esta perspectiva filosófico-teológica, en realidad el "pálido reflejo" de las formas polítcas de lo divino. Como bien explica Gershom Scholem en Las grandes tendencias de la mística judía sobre el libro canónico de la cábala judía, el Zóhar, cuando Dios que se halla oculto e incognoscible, como Ein Sof, sale de su ocultamiento y entra en relación con el universo, se forman los atributos divinos que representan los aspectos de su naturaleza divina: es la forma del develamiento de lo oculto y el origen de la creación del mundo. Pero, como bien dice Scholem, para la cábala y la mística judía, estas no tienen el valor de simples metáforas sino todo lo contrario:

"Para el filósofo medieval, la alusión de las Escrituras al 'brazo de Dios' era simplemente una analogía del brazo humano, que es el único que existe; es decir que 'brazo de Dios' no es más que una figura retórica. Para el místico, en cambio, el brazo de Dios representa una realidad superior al brazo humano. Este último existe sólo en virtud de la existencia de aquél"' (Scholem 2000, 230).

J. H. Laenen en su trabajo introductorio a la mística judía recoge las palabras de Scholem y amplía su explicación: 
"Cuando la Biblia o la literatura rabínica hablan de 'el brazo de Dios', los cabalistas toman esa afirmación de un modo literal: la realidad divina contiene un aspecto que coincide con el término 'brazo'. Más aún, el único brazo real es el brazo de Dios. El brazo humano, tal como viene a mostrarse en nuestro mundo, no es más que un débil reflejo de esa suprema realidad. En otras palabras, cuando la Biblia dice 'brazo de Dios', no está ofreciendo una descripción antropomórfica de Dios, sino que es al contrario; cuando una persona, un varón o mujer, habla de su propio cuerpo utilizando términos como 'brazos', 'piernas', etc., lo que hace es una descripción teomórfica (es decir, 'con forma divina') de una persona” (Laenen 2006, 90).

Es esta descripción teomórfica la que, trasladada a nuestra teología política, inaugura un nuevo sendero de trabajo ya que nos cambia, o nos propone cambiar, la concepción que tenemos hasta aquí del mundo y de la manera de pensar el mundo en su relación con la dimensión de lo divino. En este sentido, lo terrenal y mundano pasa a ser un pálido reflejo (“débil reflejo”) del mundo divino. Ante esta concepción, ¿qué serían entonces el Mesías o los ángeles? Tal vez, y más ahora que antes, el puente mediador entre ambas realidades que vuelve real y posible el mundo terrenal y, en consecuencia, las categorías humanas (profanas) y políticas. Ellos, el Mesías o los ángeles, no son el reflejo de lo divino en el mundo terrenal, sino la esperanza divina de lo por-venir en el primer caso, y de la comunicabilidad y construcción de sentido en el segundo.

Siguiendo por esta línea de análisis, debemos recordar un pasaje bíblico fundamental que se encuentra en el libro del Génesis ${ }^{16}$, en donde se relata la primera creación del ser humano en relación directa con la forma divina de Dios: "Y dijo Dios: hagamos al humano a nuestra imagen, a nuestra semejanza"17 (1:26). El ser humano es creado a imagen y semejanza de Dios dice el texto bíblico, y no a la inversa. Como escribe Laenen: "El hecho de que los hombres tengan partes corporales sólo puede entenderse sobre la base de esta realidad superior divina. En esta línea, el brazo humano no es más que el símbolo que alude al brazo de Dios, que es ahora algo real y existente en el mundo de la divinidad" (Laenen 2006, 90).

\footnotetext{
${ }^{16}$ Para las citas bíblicas del libro del Génesis, aunque traducimos directamente del hebreo, utilizamos como referencia la extraordinaria traducción realizada por Daniel Colodenco: Génesis: el origen de las diferencias.

${ }^{17}$ La utilización del plural en el hebreo de este pasaje, problema de histórica controversia sobre su significado, es fundamental para nuestros objetivos tomando en cuenta que según varias exégesis judías y especialmente en Bereshit Rabbah (o El Gran Génesis, que es un Midrash, compilación de explicaciones y enseñanzas, que comprende una colección de interpretaciones homiléticas rabínicas del Libro de Génesis), el plural, como explica Colodenco, "se debe a que Dios se aconsejó con los ángeles administradores (Malajei HaSharet) antes de crear al ser humano. Este dato no menor nos permite ver otra referencia al poder político de los seres angelicales en el mundo de las decisiones divinas.
} 
De esta manera, para la realidad de la mística judía, seríamos el reflejo de lo divino, porque la concepción del ser humano se crea a imagen y semejanza de lo divino: somos, desde esta lectura, el pálido espejo (o reflejo) incompleto y profano de la divinidad. $\mathrm{O}$, tal vez, la materialización de aquello que no contiene materia en sí misma: la materialización de lo inmaterial en el mundo de lo profano, mundo de la finitud. A través de esta perspectiva desde la escritura hasta las instituciones políticas se transforman ahora también en el reflejo imperfecto de la escritura y las instituciones divinas, o de su lenguaje.

\section{VI.}

Finalmente, quisieramos terminar estas reflexiones señalando que creemos que hay una aporía en la concepción schmittiana de la teología política que ha sido dejada de lado en las más importantes interpretaciones sobre el tema. Esta es la del traspaso o corrimiento dentro de la teoría del Estado, citando a Schmitt, del "Dios omnipotente en el legislador todopoderoso" (Schmitt 2009, 37), en donde se termina intercambiando la idea de Dios todopoderoso por la del Estado. Desde la tradición judía, Dios se revela a través de diferentes formas hasta que entrega la Ley, representada tradicionalmente por las Tablas de los Mandamientos o el Decálogo y luego por la Torá (Pentateuco). Estas Tablas que se heredan y constituyen el corazón de la Ley mosaica ni siquiera son las Tablas escritas por Dios según el texto bíblico, sino las Segundas Tablas, las copias en manos del hombre, Moisés, luego que este rompiera las Primeras al ver al pueblo de Israel adorando el becerro de oro luego de bajar del Monte Sinaí (Éxodo 32). Grandes reflexiones se han hecho sobre la copia como origen de la escritura: un ejemplo de ello es la realizada por Maurice Blanchot en su libro La amistad, en donde dice que la escritura para el judaísmo es siempre lo "escrito dos veces", la relación entre las primeras y las segundas Tablas, y por ello es siempre una palabra "de antemano destruida de lo que el hombre aprende a extraer la exigencia que debe hablarle" (Blanchot 2007, 206). Otra fundamental reflexión es la de George Steiner en su Lección de los Maestros en donde escribe: "La Ley mosaica tiene su origen en un segundo conjunto de Tablas no tocadas por la mano de Dios" (Steiner 2011, 39), y por ello al ser escritas por la mano del hombre detienen, inmovilizan e institucionalizan el discurso. ${ }^{18}$

Dicho esto podríamos preguntarnos: ¿Cómo constituir o traspasar la idea de Dios que se oculta sobre la idea del Estado que es pura presencia, monopolio de la violencia física legítima y finitud histórica? Y, por otro lado, ¿cómo hacer de una Ley dada a los hombres y para los hombres un fundamento secular si ya

${ }^{18}$ Aunque no directamente, es fundamental el análisis de las Tablas de la Ley que realiza Massimo Cacciari en su libro Íconos de la Ley (Cacciari 2009). 
la Ley se presenta de manera mundana pero llevando consigo la huella de la revelación divina?

Con unas últimas reflexiones sobre estas preguntas nos gustaría terminar nuestro texto. En primer lugar, fue Friedrich Schiller quien observó la aporía de la igualación entre Dios y el Estado cuando reflexionó sobre la figura de Moisés en su ensayo La misión de Moisés (Schiller 1991). Vale la pena decir que es un texto inspirado, como bien reconoce Jan Assmann, en el trabajo poco conocido de Karl Leonhard Reinhod sobre los misterios hebreos del siglo XVIII quien descubre el paralelismo entre los misterios egipcios sobre "la deidad única que todo lo abarca, sin nombre e invisible" (Assmann 2015, 318) que no puede revelarse al común del pueblo sino sólo a los sabios que son capaces de comprender, no sin esfuerzo y trauma, que nada se puede decir ni enseñar de Dios porque nada se puede conocer de Él, de la misma manera que para los místicos judíos de la cábala existe una parte de Dios que ni siquiera tiene nombre, que es el Ein Sof, en donde Dios es incognoscible e inhaprensible, y que solamente a partir de sus propias emanaciones o manifestaciones (el mundo de las sefirot) es posible saber, aprehender y acceder a lo divino. Sin embargo, al final del camino -o mejor dicho: en el inicio de éste- nada sabemos de Dios. Es por ello que el gran misterio ("misterio mayor") guarda ya en sí mismo una incompatibilidad irreconciliable entre Dios y el Estado.

Reinhold dirá, según Assmann, que el verdadero papel de Moisés consistió en tomar esta verdad que ya conocían los sabios egipcios para "hacer partícipe de tal verdad a un pueblo entero" (Assmann 2015, 318). Schiller ve también, retomando esta tesis, "la máxima expresión de lo sublime en el carácter anónimo, unitario y universal de Dios" (Assmann 2015, 319; Schiller 1991, 43-44) pero nos llama la atención sobre la disfuncionalidad política de esta idea a partir de la cual es imposible construir un Estado, y con ello de su aporía, porque si se divulga esta idea y se comprende en toda su extención esta realidad incognoscible de Dios que no tiene ni siquiera Nombre, ello "supondría la ruina del orden político" (Assmann 2015, 319). Es por ello necesario mantenerla en secreto y revestida de misterio. Fue Moisés quien transformó, o redujo, esa idea mística a un Dios de un pueblo y a una teología política pública que pudiera sostenerse sobre la base del cumplimiento de los preceptos al mismo tiempo que se transforme en el fundamento de una constitución política, ética y social. Él mismo fue el inicio de un proceso de racionalización que tomó luego, con el rabinismo por un lado, y con Maimónides -y la filosofía judía racional- por otro, el camino de un Dios filosófico: como escribe Assmann leyendo a Schiller, "una realización política de la verdad divina" (Assmann 2015, 321).

En segundo lugar, y por último, regresando al problema de las dos Tablas de la Ley, podríamos decir que no hay un proceso de secularización en el mundo judío, porque las Segundas Tablas fueron escritas directamente de la mano de 
Moisés, pero allí habita una huella divina a través de la cual, para la mística judía, se puede acceder a la divinidad. ${ }^{19}$ La huella es el suave eco de la voz divina que entra al mundo de los hombres a través de la mano del hombre que talla sobre la piedra las Segundas Tablas de la Ley. Esa huella no se ha borrado, es la huella de la divinización del Mundo, y lo que nos permite pensar, entonces, que la Ley siempre guarda consigo el secreto del poder soberano divino.

${ }^{19}$ Tal vez, y esta es una tesis futura a desarrollar, lo más cercano a una secularización dentro de la tradición judía es la constitución del Estado de Israel, no sin comprender las complejidades inherentes a una institución política que se constituye manifiestamente desde un carácter teológico, o teológico-político: prueba de ello es la Declaración de Independencia de Israel. 


\section{BIBLIOGRAFIA}

Agamben, Giorgio y Coccia, Emanuele (Editores). 2009. Angeli. Ebraismo, Cristianesimo, Islam. Vicenza: Neri Pozza.

Agamben, Giorgio. 2004. Estado de excepción. Homo sacer, II, I. Buenos Aires: Adriana Hidalgo editora.

Assmann, Jan. 2012. "Monoteísmo e iconoclastia como teología política". En Otero, Carlos A (Editor). Iconoclastia. La ambivalencia de la mirada. Madrid: La Oficina de Arte y Ediciones.

Assmann, Jan. 2015. Poder y salvación. Teologia y política en el Antiguo Egipto, Israel y Europa. Madrid: Abada editores.

Barker, Margaret. 1992. The Grat Angel. A Study of Israel's second God. Kentucky: Westminister John Knox Press.

Baron, Salo W. 1965. Grandes épocas e ideas del pueblo judío. VI: La época moderna. Buenos Aires: Paidós.

Baron, Salo W. 1968a. Historia social y religiosa del pueblo judio. Volumen II: Época Antigua, Parte II. Buenos Aires: Paidós.

Baron, Salo W. 1968b. Historia social y religiosa del pueblo judío. Volumen V: Controles y conflictos religiosos. Buenos Aires: Paidós.

Bensussan, Gérard. 2014. ¿Qué es la filosofía judía?. Buenos Aires: Lilmod-Prometeo.

Blanchot, Maurice. 2007. La amistad. Madrid: Trotta.

Brenner, Michael. 2012. Breve historia de los judios. Buenos Aires: La Marca editora.

Cacciari, Massimo. 2009. Íconos de la Ley. Buenos Aires: Ediciones La Cebra.

Cohen, Gerson D. 1965. Grandes épocas e ideas del pueblo judío. III: La época talmúdica. Buenos Aires: Paidós.

Colodenco, Daniel. 2006. Génesis: el origen de las diferencias. Buenos Aires: Lilmod.

Dominguez, Atilano (Comp.). 1995. Biografías de Espinoza. Madrid: Alianza.

Galli, Carlo. 2011. La mirada de Jano. Ensayos sobre Carl Schmitt. Buenos Aires: Fondo de Cultura Económica.

Guerrero, Rafael Ramón. 2004. Filosofías árabe y judía. Madrid: Editorial Síntesis.

Idel, Moshé. 2005. Cábala. Nuevas perspectivas. Madrid: Ediciones Siruela.

Kohler, Kaufmann .1906. "Miracle”. Jewish Encyclopedia, Volume 8.

Kraemer, Joel L. 2012. Maimónides: vida y enseñanzas del gran filósofo judío. Buenos Aires: Kairós.

Laenen, J. H. 2006. La mística judía. Una introducción. Madrid: Trotta.

Ludueña Romandini, Fabián. 2010. La comunidad de los espectros. I: Antropotecnia. Buenos Aires: Miño y Dávila editores. 
Maimónides. 1991. Tratado de los atributos de la ley divina [edición facsimilar de la edición original del año judío 5412]. Barcelona: Riopiedras.

Maimónides. 2005. Guía de perplejos. Madrid: Trotta.

Marramao, Giacomo. 1998. Cielo y tierra. Genealogía de la secularización. Barcelona: Paidós.

Metz, Johann Baptist. 2002. Dios y tiempo. Nueva teología política. Madrid: Editorial Trotta.

Nietszche, Friedrich. 2009. La gaya ciencia. Barcelona: Ariel.

Peterson, Erik. 1999. El monoteísmo como problema político. Madrid: Trotta.

Rosenzweig, Franz. 2006. La estrella de la redención. Salamanca: Ediciones Sígueme.

Schiavone, Aldo. 2012. Ius. La invención del derecho en Occidente. Buenos Aires: Adriana Hidalgo editora.

Schiller, Johann Christoph Friedrich von. 1991. Escritos de Filosofía de la Historia. Murcia: Univeridad, Secretariado de Publicaciones.

Schmitt, Carl. 2009. Teología política. Madrid: Trotta.

Scholem, Gershom. 2000. Las grandes tendencias de la mística judía. Madrid: Ediciones Siruela.

Segal, Alan F. 2012. Two powers in heaven. Early Rabbinic reports about Christianity and Gnosticism. Texas: Baylor University Press.

Steiner, George. 2011. Lecciones de los Maestros. Buenos Aires: Debolsillo.

Taub, Emmanuel. 2013. Mesianismo y redención. Prolegómenos para una teología política judía. Buenos Aires: Miño y Dávila editores.

Taub, Emmanuel. 2016. "La guerra santa y el herem bíblico: una arqueología del poder soberano". En Acerbi, Juan; Borisonik, Hernán; Ludueña Romandini, Fabián (Editores). Inseguridad y catástrofes. Un abordaje desde la teoría política. Ushuaia: Ediciones UNTDF.

Taub, Emmanuel. 2018. "Los ángeles y el poder celestial: el racionalismo de Maimónides versus el misticismo y la duplicidad del trono". Universitas Philosophica, Año. 35, No. 70, enero-junio: 103-129.

Taubes, Jacob. 2007. "Teología y teoría política”. En Del culto a la cultura. Buenos Aires: Katz Editores. 